\title{
Ten years on
}

\author{
Fiona Godlee editor in chief, The BMJ
}

It's 10 years this week since I wrote my first editor's choice (doi:10.1136/bmj.330.7492.0-h). It has been an exciting decade to edit a medical journal: a time of great change in healthcare and research, in the ways we communicate, in doctors' working lives, and in what it means to be a patient. Underlying those changes have been quiet but dramatic shifts in the culture of medicine, away from longstanding hierarchies and dearly held certainties towards greater transparency and uncertainty, bringing with them a heady mixture of progress and discomfort.

Throughout the decade The BMJ has aimed to help doctors make better decisions, as clinicians and as leaders of health systems. This now means involving patients, because among the most important changes in the culture of medicine has been the recognition that decisions that don't have patients at their centre cannot be considered good (thebmj.com/campaign/patientpartnership).

The push for greater partnership with patients is the latest addition to The BMJ's campaigns, in all of which we have sought to make good use of the journal's unique character as an academic journal and a magazine. We recognise the risks in this approach but also the opportunity to make a difference by focusing both science and journalism on issues that in our view need debate and change.

Inevitably we will not have pleased everyone in the issues we have chosen to focus on. As well as patient partnership, the list includes evidence based medicine, death and dying, research methods and reporting, research misconduct, open access, conflict of interest, relations with and the role of industry, drug and device regulatory failure, hidden data from clinical trials, too much medicine, access to patient records and clinical performance data, social inequality, commercialisation and corruption in healthcare, and the threat of climate change to health.

Along the way we have tried to be the change we wish to see in the world, to paraphrase Gandhi. While pushing for patient partnership, we have challenged ourselves to partner with patients in creating content, asking authors of research and education articles how they involved patients in the work, and having patients as advisers and peer reviewers (doi:10.1136/ bmj.g3726). In calling for an end to industry's involvement in the education of doctors, we have set a new-and some say impossible - standard of no relevant financial conflicts of interests for authors of clinical education articles (doi:10.1136/ bmj.g7197). In pushing for more openness in all walks of healthcare we have embraced openness ourselves: open peer review, open access to research, open data.

So, can we hope to see more research that is independent of financial interests, and medical education that is free from commercial bias? What hopes for better governance of healthcare, stronger clinical leadership, more resilient and effective health systems? How can we achieve better application of evidence in policy and practice? Whatever better future the next decade brings, my hope is that the journal and its readers, authors, and reviewers will have played their part. 